\title{
Coronavirus (COVID-19) Pandemic and Health Workers of an Ethnic Group-A Slant on a Shocking Report
}

\author{
Zakaria Barsoum ${ }^{1}$ \\ Accepted: 17 July 2020 / Published online: 18 July 2020 \\ (C) Springer Nature Switzerland AG 2020
}

\begin{abstract}
The coronavirus (COVID-19) pandemic is an unprecedented challenge to all health care professionals. I present a brief report on a shocking report, released recently in the UK on this matter.
\end{abstract}

Keywords COVID-19 $\cdot$ Black, Asian and minority ethnic (BAME) $\cdot$ Health workers $\cdot$ UK

The coronavirus (COVID-19) pandemic is a colossal challenge to health care system worldwide. Nobody seems immune to COVID-19 in the absence of effective specific vaccine. People from all walks of life can be afflicted with the pandemic. The question is: are there cohorts in the general population more vulnerable to COVID-19?

The recent report of Cook et al. [1] was shocking; there were 106 fatalities among the UK National Health Service (NHS) staff, 33\% nurses, 25\% health care support workers and $17 \%$ doctors. Deceased doctors of Black, Asian and minority ethnic (BAME) comprised $94 \%$ of the total deaths figures in the UK, notwithstanding that they represent $44 \%$ of the workforce. The trend was similar among nurses; $71 \%$ of COVID-19 fatalities were in the BAME group, although they account for $20 \%$ of the workforce.

For the general UK population, a similar outcome has emerged; the report indicated that $34 \%$ of COVID-19 admissions to intensive care units were in the BAME group. Nonetheless, they constitute $17 \%$ of the UK population [1].

The causes for the excess mortality and COVID-19 contraction among health workers of BAME ethnicity are not clear and warrant further elucidation. A better understanding of the geography, potential exposure and personal demographic characteristics should be made available to allow the identification of explanatory factors [2].

This article is part of the Topical Collection on Covid-19

Zakaria Barsoum

doctorzakaria@yahoo.com

1 Paediatric Department, South West Acute Hospital, 124 Irvinestown Rd, Enniskillen BT 74 6DN, Northern Ireland
Relative to NHS, the British Dental Association (BDA) quote that $28 \%$ of UK dentists are of BAME origin. Dental practice cannot be practised remotely, placing BAME dentists at further increased risks of contracting CoVID-19. There is, however, little evidence on the risks posed to the BAME community within the dental profession [3].

Data on ethnicity in patients with COVID-19 in the published medical literature remains limited. However, emerging data from the grey literature and preprint articles suggest BAME individuals are at an increased risk of acquiring COVID-19 infection compared with White individuals and also worse clinical outcomes from COVID-19 [4].

From 1 March 2020 up to 5pm on 21 April 2020, Aldridge et al. undertook indirect standardisation of international and UK data (using the whole population of England as the reference) to produce ethnic specific standardised mortality ratios (SMRs) adjusted for age and geographical region. The analysis supported the evidence that BAME people are at increased risk of death from COVID-19 even after adjusting for geographical region [5].

Potential causes are biological, medical and socio-economical. Living in tight family units and lack of proper social distancing may play a role in widespread transmission of COVID19 among BAME health workers. Prevalence of other diseases among BAME health workers such as diabetes and hypertension may also compound the situation. Working in frontline jobs may exponentially increase the risks and place BAME health workers in jeopardy of COVID-19 contracting. Family members of this group are at increased risks of COVID-19, placing health workers at immense emotional pressures.

In one study, multivariate logistic regression models including age, sex and ethnicity did not show that addition of cardio-metabolic factors (diabetes, hypertension, high 
cholesterol, prior myocardial infarction, smoking and body mass index (BMI)); 25(OH)-vitamin D; poor diet; Townsend deprivation score; housing (home type, overcrowding) or behavioural factors (sociability, risk taking) attenuated sex/ ethnicity associations with COVID-19 status, [6] requiring more comprehensive assessment of the complex economic, social and behavioural differences.

Uncertainty is another concern. Among 200 respondents to a questionnaire through Leicester Asian Doctors Society and Leicester Asian Nurses Society, more than $70 \%$ were anxious about their role during this pandemic. [7]

In the short and long run, BAME health workers await expositions about their vulnerability to the disease. I believe further investigations to explicate this issue are increasingly warranted. COVID-19-related research should now focus at this sector of the population, their proneness to COVID-19, based on racial, occupational, socio-economic and possibly genetic predisposition. Scholars may not be able to find simple answers to this conundrum why BAME health workers seem to be more vulnerable to COVID-19.

The head of the British Medical Association has recently called on the government to urgently investigate the matter.

\section{Compliance with Ethical Standards}

Conflict of Interests The author declares that he has no conflict of interest.

Ethical Approval Not required.

Informed Consent Not required.

\section{References}

1. Cook T, Kursumovic E, Lennane S. Exclusive: deaths of NHS staff from COVID-19 analysed. HSJ 2020. https:/www.hsj.co.uk/ exclusive-deaths-of-nhs-staff-from-covid-19-analysed/7027471. article.

2. Peate I. Why are more BAME people dying from COVID-19? BJN;2020. https://doi.org/10.12968/bjon.2020.29.10.545.

3. Trivedy C, Mills I, Dhanoya O. The impact of the risk of COVID-19 on Black, Asian and minority ethnic (BAME) members of the UK dental profession. Br Dent J. 2020;228:919-22.

4. Pan D, Sze S, Jatinder S Minhas et.al, The impact of ethnicity on clinical outcomes in COVID-19: a systematic review. EClinicalMedicine 2020. https://doi.org/10.1016/j.eclinm.2020. 100404.

5. Aldridge RW, Lewer D et al. Black, Asian and minority ethnic groups in England are at increased risk of death from COVID-19: indirect standardisation of NHS mortality data. Wellcome Open Res. 2020. https://doi.org/10.12688/wellcomeopenres.15922.2.

6. Raisi-Estabragh Z, McCracken C, Bethell MS et al. Greater risk of severe COVID-19 in Black, Asian and minority ethnic populations is not explained by cardiometabolic, socioeconomic or behavioural factors, or by $25(\mathrm{OH})$-vitamin D status: study of 1326 cases from the UK Biobank. J Public Health (Oxf). 2020. https://doi.org/10. 1093/pubmed/fdaa095.

7. Moorthy A, Sankar TK. Emerging public health challenge in UK: perception and belief on increased COVID19 death among BAME healthcare workers. J Public Health (Oxf) 2020. https://doi.org/10. 1093/pubmed/fdaa096.

Publisher's Note Springer Nature remains neutral with regard to jurisdictional claims in published maps and institutional affiliations. 